\title{
Simultaneous EEG and fMRI Reveals a Causally Connected Subcortical-Cortical Network during Reward Anticipation
}

\author{
Michael M. Plichta, ${ }^{1 \star}$ Isabella Wolf,, ${ }^{2,5}$ Sarah Hohmann, ${ }^{2}$ Sarah Baumeister, ${ }^{2}$ Regina Boecker, ${ }^{2}$ Adam J. Schwarz, ${ }^{6}$ \\ Maria Zangl, ${ }^{1}$ Daniela Mier, ${ }^{3,7}$ Carsten Diener, ${ }^{4,7}$ Patric Meyer, ${ }^{4,7}$ Nathalie Holz, ${ }^{2}$ Matthias Ruf, ${ }^{5}$ Martin F. Gerchen, ${ }^{3,7}$ \\ David Bernal-Casas, ${ }^{3,7}$ Vasil Kolev, ${ }^{8}$ Juliana Yordanova, ${ }^{8}$ Herta Flor, ${ }^{4,7}$ Manfred Laucht, ${ }^{2}$ Tobias Banaschewski, ${ }^{2}$ \\ Peter Kirsch, ${ }^{3,7}$ Andreas Meyer-Lindenberg, ${ }^{1}$ and Daniel Brandeis ${ }^{2,9,10,11}$ \\ Central Institute of Mental Health, Medical Faculty Mannheim/Heidelberg University, Departments of ${ }^{1}$ Psychiatry and Psychotherapy, ${ }^{2}$ Child and \\ Adolescent Psychiatry and Psychotherapy, ${ }^{3}$ Clinical Psychology, ${ }^{4}$ Cognitive and Clinical Neuroscience, and ${ }^{5}$ Neuroimaging, 68159 Mannheim, Germany, \\ ${ }^{6}$ Tailored Therapeutics, Eli Lilly and Company, Indianapolis, Indiana 46285, ${ }^{7}$ Bernstein-Center for Computational Neuroscience Heidelberg-Mannheim, \\ 68159 Mannheim, Germany, ${ }^{8}$ Bulgarian Academy of Sciences, Institute of Neurobiology, 1113 Sofia, Bulgaria, ${ }^{9}$ Department of Child and Adolescent \\ Psychiatry, University of Zurich, 8032 Zurich, Switzerland, ${ }^{10}$ Center for Integrative Human Physiology, University of Zurich, 8057 Zurich, Switzerland, and \\ ${ }^{11}$ Neuroscience Center Zurich, University of Zurich and ETH Zurich, 8057 Zurich, Switzerland
}

Electroencephalography (EEG) and functional magnetic resonance imaging (fMRI) have been used to study the neural correlates of reward anticipation, but the interrelation of EEG and fMRI measures remains unknown. The goal of the present study was to investigate this relationship in response to a well established reward anticipation paradigm using simultaneous EEG-fMRI recording in healthy human subjects. Analysis of causal interactions between the thalamus (THAL), ventral-striatum (VS), and supplementary motor area (SMA), using both mediator analysis and dynamic causal modeling, revealed that (1) THAL fMRI blood oxygenation level-dependent (BOLD) activity is mediating intermodal correlations between the EEG contingent negative variation (CNV) signal and the fMRI BOLD signal in SMA and VS, (2) the underlying causal connectivity network consists of top-down regulation from SMA to VS and SMA to THAL along with an excitatory information flow through a THAL $\rightarrow \mathrm{VS} \rightarrow \mathrm{SMA}$ route during reward anticipation, and (3) the EEG CNV signal is best predicted by a combination of THAL fMRI BOLD response and strength of top-down regulation from SMA to VS and SMA to THAL. Collectively, these findings represent a likely neurobiological mechanism mapping a primarily subcortical process, i.e., reward anticipation, onto a cortical signature.

\section{Introduction}

Functional magnetic resonance imaging (fMRI) studies have identified a neural circuit underlying reward anticipation in humans and nonhuman species. This circuit includes the ventral striatum (VS) as a pivotal structure that is innervated by mesostriatal dopamine and linked to the anterior cingulate cortex (ACC), supplementary motor area (SMA), insula, and thalamus (THAL; Knutson et al., 2001a,b; Kirsch et al., 2003; Knutson and Cooper, 2005; Liu et al., 2011). Anticipatory VS activation has been shown to be a reliable fMRI assay within and across subjects

Received Feb. 11, 2013; revised Aug. 1, 2013; accepted Aug. 3, 2013.

Author contributions:M.M.P., A.J.S., H.F., M.L., T.B., P.K., A.M.-L., and D.B. designed research;M.M.P., I.W., S.H., S.B., R.B., M.Z., D.M., C.D., P.M., N.H., and D.B. performed research; M.R., H.F., and T.B. contributed unpublished reagents/analytic tools; M.M.P., S.H., S.B., R.B., M.F.G., D.B.-C., V.K., J.Y., and D.B. analyzed data; M.M.P., I.W., S.H., S.B., R.B., A.J.S., M.Z., D.M., M.F.G., D.B.-C., V.K., J.Y., P.K., A.M.-L., and D.B. wrote the paper.

This work was supported by the German Ministry of Education and Research (BMBF, 01GQ1003B), the Deutsche Forschungsgemeinschaft (SFB 636), and NEWMEDS. The work leading to these results has received funding from the Innovative Medicines Initiative Joint Undertaking under Grant agreement no. 115008. We thank Dagmar Gass, Heike Schmidt, Vera Zamoscik, Christine Niemeyer, and Stefanie Rechtsteiner for assistance with data collection.

${ }^{*}$ M.M.P. and I.W. contributed equally to this work.

Correspondence should be addressed to Dr Michael M. Plichta, Central Institute of Mental Health, Department of

Psychiatry and Psychotherapy, Medical Faculty Mannheim/Heidelberg University, J5, 68159 Mannheim, Germany. E-Mail:Michael.Plichta@zi-mannheim.de.

DOI:10.1523/JNEUROSCI.0631-13.2013

Copyright $\odot 2013$ the authors $\quad 0270-6474 / 13 / 3314526-08 \$ 15.00 / 0$
(Plichta et al., 2012), sensitive to genetic variants (Kirsch et al., 2006; Forbes et al., 2009; Hahn et al., 2011) and linked to impulsivity and (an)hedonic states in clinical and nonclinical populations (Kirsch et al., 2006; Scheres et al., 2007; Hahn et al., 2009; Plichta et al., 2009; Forbes et al., 2010; Juckel et al., 2012).

Despite considerable fMRI research on the neural correlates of reward anticipation, there are only relatively few studies focusing on the time-resolved neurophysiological signatures of this process. Previous studies have identified several event-related potentials (ERPs) derived from the electroencephalogram (EEG) relevant to reward processing (Broyd et al., 2012a) among those the contingent negative variation $(\mathrm{CNV})$, a slow frontocentrally negative electrical brain activity, which is directly related to expectation and preparation of motivated responses (Walter et al., 1964).

The CNV amplitude has been shown to increase with reward in animal and human studies (Boyd et al., 1979; Pierson et al., 1987; Kotani et al., 2001; Broyd et al., 2012b; Capa et al., 2013) and source analysis (Gómez et al., 2003) suggested important generators of the CNV in the ACC, SMA, and posterior regions including the inferior parietal cortex (IPC). This has been validated in a simultaneous EEG-fMRI study (Nagai et al., 2004).

In the context of reward processing, ERP and fMRI reward anticipation markers have been studied only separately. There- 
fore, the interrelation between them is still unknown. The primary goal of the present study was to investigate the relationship between EEG and fMRI signals in response to a well established fMRI reward anticipation paradigm with simultaneous EEGfMRI data recording.

By using conventional general linear model (GLM) analysis and analysis of causal interactions between the THAL, VS, and SMA based on mediator analysis and dynamic causal modeling (DCM) we show that (1) THAL fMRI BOLD activity is mediating intermodal correlations between the EEG CNV signal and the fMRI BOLD signal in SMA and VS, (2) the underlying causal connectivity network consists of top-down regulation from SMA to VS and SMA to THAL along with an excitatory information flow through a THAL $\rightarrow \mathrm{VS} \rightarrow \mathrm{SMA}$ route during reward anticipation, and (3) the EEG CNV signal is best predicted by a combination of THAL fMRI BOLD response and strength of top-down regulation from SMA to VS and SMA to THAL.

\section{Materials and Methods}

Subjects. Eighteen healthy right-handed subjects participated in the experiment. For technical reasons, data from four subjects had to be discarded: one subject had an insufficient number of artifact-free EEG trials; two subjects showed significant outlier mean CNV values; and one subject produced significant outlier fMRI results (for outlier analyses, see below). The final sample consisted of 14 subjects ( 8 males and 6 females) with a mean age of 24 years $(\mathrm{SD}=4.24)$.

All participants were informed about the nature of the experiment before providing written informed consent. The combined EEG-fMRI investigation of healthy participants and the entire experimental procedure was in accordance with the Declaration of Helsinki and was approved by the local ethics committee of the Medical Faculty Mannheim of Heidelberg University.

Paradigm. We used a modified version of a monetary reward anticipation task (Kirsch et al., 2003) that has been shown to reliably and robustly activate the VS (Plichta et al., 2012). In this paradigm, the subject must respond sufficiently fast to a light-flash (duration $=100 \mathrm{~ms}$ ) on the visual display screen. The upcoming flash was signaled by a stimulus $\mathrm{S} 1$ that informed the subject about the consequences of their response to the flash stimulus S2. Stimulus onset asynchrony between S1 and S2 was variable (3-5s) with a mean of $4 \mathrm{~s}$. After the response of the subject to the flash and an additional time lag of $200 \mathrm{~ms}$, the outcome was reported on the screen for $1.5 \mathrm{~s}$. After an intertrial interval of $2 \mathrm{~s}$ plus an reaction time (RT)-dependent value that ensured equal trial durations [i.e., maximum of RT window ( $1 \mathrm{~s}$ ) minus actual RT], the next trial started.

The two conditions were: (1) monetary reward anticipation (S1: smiley) where the subject could win 0.50 Euros if the response was sufficiently fast, or (2) control condition (S1: scrambled smiley) where only a verbal feedback was given. During the outcome phase the participants saw the outcome of the latest trial ("+ $+0.50 €$ ”; “+ $+0.00 €$ ", or "Fast response!"; "Too slow") as well as their cumulative sum total at that point in time. In this event-related paradigm, each of the above conditions was presented 50 times in a pseudo-randomized order. Additionally, we used so-called boost trials to maximize reward processing through uncertainty and to ensure task engagement (Riba et al., 2008), i.e., after successful performance the subject won unexpectedly 2 Euros instead of 0.50 Euros. Boost trials occurred after eight wins on average. The RT window for a sufficiently fast response was adaptively tailored to the individual RTs to collect a comparable number of winning trials across subjects $(\sim 60 \%)$. After the final trial presentation, a black screen was presented for $12 \mathrm{~s}$. The total run length was 14 min $52 \mathrm{~s}$.

Data acquisition. The EEG was recorded inside the scanner using a 5 $\mathrm{kHz}$ sampling rate, $32 \mathrm{mV}$ input range and $0.1-250 \mathrm{~Hz}$ bandpass filters. The EEG data were transmitted from two MR-compatible BrainAmp amplifiers (Brain Products) via optic fibers outside the scanner room. Sixty equidistantly spaced silver/silver chloride $(\mathrm{Ag} / \mathrm{AgCl})$ scalp electrodes recorded the EEG signal using MR-compatible caps (Easycap) with twisted and fixed electrode cables. EEG montage was based on a selection of 10-20 system positions. To account for different head circumference, three different cap sizes were available. F1 served as recording reference, F2 was the ground electrode. An additional electrooculogram (EOG) electrode was placed below the outer canthus of each eye and two further electrodes (one right to the sternum and one on the left chest close to the heart) to record the electrocardiogram (ECG). Electrode impedances were kept $<20 \mathrm{k} \Omega$, except ECG, and EOG electrodes $(<30 \mathrm{k} \Omega)$ as well as Reference and Ground $(<10 \mathrm{k} \Omega)$. The EEG was monitored while scanning using online correction software (RecView, Brain Products).

EEG analysis. EEG data were corrected for the MRI gradient (Allen et al., 2000) and cardioballistic artifacts (Allen et al., 1998) using standard template subtraction procedures as implemented in the Brain Vision Analyzer software 2.0 (Brain Products). EEG data were digitally low-pass filtered $(70 \mathrm{~Hz})$ and down sampled to $500 \mathrm{~Hz}$. After exclusion of physical artifacts via raw data inspection, infomax independent component analysis (ICA) was used to remove ocular artifacts (blinks, movements), remaining cardioballistic artifacts (Debener et al., 2008) and residual artifacts related to gradient modulation (Brain Vision Analyzer software 2.0, Brain Products). EEG data were re-referenced to an average reference, baseline corrected by subtracting the average over a $500 \mathrm{~ms}$ prestimulus interval and low-pass filtered with a cutoff of $30 \mathrm{~Hz}$. Segmentation into ERP epochs of $4.5 \mathrm{~s}$ began $500 \mathrm{~ms}$ before stimulus onset and ended $4000 \mathrm{~ms}$ poststimulus onset. ERP averages for both conditions (monetary reward anticipation and control) were calculated within each and across all participants. The CNV was captured at electrode Central zero $(\mathrm{Cz})$ within two different time windows (CNV1: from 1 to $2 \mathrm{~s}$ and CNV2: from 2 to $3 \mathrm{~s}$ poststimulus presentation). Dividing the CNV into successive $1 \mathrm{~s}$ time window preceding the (earliest) target onset was based on previous work (van Leeuwen et al., 1998; Nagai et al., 2004) because these CNV phases may reflect partly different neural processes (Rohrbaugh et al., 1976). The CNVs were exported as mean amplitudes for each time window.

fMRI image acquisition. All MRI sequences were performed on a 3-tesla whole-body scanner (Magnetom Trio, Siemens Medical Solutions). Functional data were acquired using $\mathrm{T} 2{ }^{\star}$-weighted single shot gradient echo planar imaging (EPI) sequences with the following scanning-parameters: $\mathrm{TR} / \mathrm{TE}=2210 / 28 \mathrm{~ms}$; flip angle $=90^{\circ} ; 36$ axial slices (slice thickness $=3 \mathrm{~mm}+1 \mathrm{~mm}$ gap) ascending, $\mathrm{FOV}=220 \mathrm{~mm} \times 220$ $\mathrm{mm}$, matrix $=64 \times 64$. Slices were oriented $\sim 20^{\circ}$ steeper than AC-PCplane. The first four EPI volumes were discarded to allow for T1 equilibration. After recording of the functional images, a high-resolution T1-weighted 3D MRI sequence was conducted (192 sagittal slices, slice thickness $1 \mathrm{~mm}$, FOV $=256 \mathrm{~mm} \times 256 \mathrm{~mm}$, matrix $=256 \times 256)$. These parameters provided whole brain coverage, including cerebellum, scalp, eyes, and nose, to avoid wrap-around artifacts. The paradigm was presented to the subject via video goggles (Resonance Technologies) controlled by the software Presentation (Neurobehavioral Systems). Behavioral data were recorded with response buttons (Current Designs).

fMRI data analyses. The fMRI data were analyzed using statistical parametric mapping (SPM8; Wellcome Trust Centre for Neuroimaging, London, UK). Preprocessing of the fMRI data included slice-time correction, motion correction, spatial normalization into Montreal Neurological Institute $[\mathrm{MNI}]$ space, resampling to $2 \times 2 \times 2 \mathrm{~mm}^{3}$, and spatial smoothing with an $8 \mathrm{~mm}$ full-width at half-maximum Gaussian kernel. Spatial normalization was performed by calculating linear (12-parameter affine) and nonlinear transformations of the mean EPI image from each time series to the SPM EPI template in MNI space, and then applying these same transformation parameters to the time series.

Statistical analyses comprised first level temporal modeling within a GLM framework to generate a 3D map corresponding to estimated regressor response amplitudes. Regressors of interest (monetary reward anticipation, control), both modeled as events with a duration of zero seconds, were convolved with the default SPM hemodynamic response function (HRF) computed as a two-parameter gamma function. Eight regressors of no-interest were included: two regressors coding the feedback and the responses (convolved with the HRF) and six motion parameters (not convolved with the HRF). For all three tasks, a high-pass filter with a cutoff frequency of $1 / 128 \mathrm{~Hz}$ was used to attenuate low-frequency 
components. All analyses were corrected for serially correlated errors by fitting a first-order autoregressive process $(\mathrm{AR}[1])$ to the error term.

For the combined analysis of EEG and fMRI data we used two different approaches. First, we calculated the mean $\mathrm{CNV}$ parameters per subject (average amplitude over predefined CNV1 and CNV2 windows; see above) and used them as covariates in the second-level analyses, revealing the correlation between the ERP difference amplitudes and fMRI brain activation during reward anticipation (as contrasted to the control condition). Second, we applied a trial-to-trial analysis: here we used the single-trial ERP amplitudes of each participant as a parametric modulator of the condition-dependent BOLD responses at the single-subject level. Contrast images from these first-level models were then introduced into a one-sample $t$ test at the second level to test for group effects.

ROI definitions. For the combined analyses of EEG and fMRI data, we defined the following regions-of-interest (ROIs). First, we defined the ventral striatum as a fusion of the "caudate head" mask taken from the WFUPickAtlas (human-atlas TD Brodmann areas+) and the "accumbens" mask from the Harvard-Oxford Subcortical Structural Atlas(implementedinFSLView3.1.8; http://www. cma.mgh.harvard.edu/fsl_atlas.html;

probability threshold was set to 50\%). The left and right VS were treated as separate ROIs. Second, we used an anatomical definition of the thalamus taken from the WFU-PickAtlas (human-atlas aal). Finally, for the SMA we used an empirical mask based on binarized second-level activation maps calculated from a published independent subject sample (Plichta et al., 2012) that was scanned twice $(N=25)$ using the original reward paradigm and the identical contrast (monetary reward anticipation $>$ control). This was done because the atlas definition of the SMA is much larger than typically observed activation foci, hence probably heterogeneous in function and likely to result in low ROI mean response values due to a mixing of strongly and weakly responding voxels.

Mediator analysis. A mediator analysis was conducted to assess whether the neural regions that show significant correlation with the ERP explain similar variance or whether certain regions subsume the impact of others. Specifically, THAL is assumed to be involved relatively early in the reward anticipation process, whereas the SMA, as a motor execution relay, might represent a relatively late component in information flow. We formally tested mediation by means of the Sobel test (Baron and Kenny, 1986) accompanied by a bootstrapping method with $N=$ 5000 bootstrap samples (Preacher and Hayes, 2004) using the PROCESS procedure (Hayes, 2012) for SPSS version 20 (IBM).

Dynamic causal modeling. To infer the causal structure of the network between the ROIs, we additionally applied bilinear DCM of the network between THAL, VS, and SMA. DCM regards the brain as a nonlinear dynamic system of interconnected neural nodes, and models experimental conditions as perturbations of the system's dynamics (Friston et al., 2003; Stephan et al., 2007, 2010). After fitting a set of a priori defined models ("model space") to the data, models are compared and the winning model with the highest log evidence relative to the others is assumed to describe the network structure with the highest accuracy and the lowest complexity (Stephan et al., 2009, 2010).

We extracted the first eigenvariate from $8 \mathrm{~mm}$ spheres around the individual peak voxels of the GLM contrast "monetary reward anticipation $>$ control" within the functional masks of THAL, VS, and SMA on the left hemisphere and constructed a model space covering all possible causal models. In all models, the monetary reward anticipation and the control condition were fixed as driving inputs into the THAL, resulting in a model space of 32 models. In addition, we assumed that both conditions activate the same network but might lead to differences in connectivity strength. Thus, the monetary reward anticipation condition was allowed to modulate the strength of all existing connections in each model to account for changes in connectivity between conditions.

After estimation, all models were entered in a group analysis with random effects Bayesian model selection (RFX BMS) and the parameters of the winning model were extracted from the individual subjects (Stephan et al., 2009).

Due to the lateralization of the CNV data which is consistent with Sobotka et al. (1992) and the right-handed task nature we focused our DCM analyses on the left hemisphere.

Data quality check. EEG and fMRI data were checked for significant outliers separately. Two strategies were used: (1) Boxplot analysis with a criterion for data exclusion of 1.5 times the interquartile range, and (2) extreme studentized deviate test with a criterion of $\alpha=0.05$. Both approaches were performed in repeated cycles of (1) outlier detection, (2) outlier exclusion, and (3) reanalysis until no more outliers were apparent. Both approaches identified the identical set of three subjects (two EEG dataset and one fMRI dataset outlier).

\section{Results}

\section{Behavioral effects}

Participants reacted significantly faster after the presentation of a monetary stimulus (monetary reward anticipation: $167.35 \mathrm{~s}$; control: $196.04 \mathrm{~s} ; t=-4.99$; $\mathrm{df}=13 ; p<0.001)$ and reached the reaction time window significantly more often during monetary trials compared with the control condition (monetary reward anticipation: 30.21; control condition: 21.07 (absolute counts); $t=4.52 ; \mathrm{df}=13 ; p=0.001)$. All participants gained money with a mean payoff of $22.78 €(\mathrm{SD}, 2.54$; range, $18-26.50 €)$.

\section{fMRI main effects}

Figure $1 A$ shows the group-level results for the contrast monetary reward anticipation $>$ control. The expected reward anticipation 
Table 1. fMRI statistics; main effects for the contrast (monetary reward anticipation > control)

\begin{tabular}{lcllll}
\hline Region & MNI & $k$ & $t$ & $z$ & $p$ \\
\hline VS-L & -624 & 297 & 14.53 & 5.83 & $<0.001$ \\
VS-R & 14182 & 277 & 14.39 & 5.81 & $<0.001$ \\
SMA-L & 0058 & 380 & 12.44 & 5.53 & $<0.001$ \\
SMA-R & 2058 & 293 & 12.75 & 5.58 & $<0.001$ \\
THAL-L & $-6-814$ & 889 & 13.03 & 5.62 & $<0.001$ \\
THAL-R & $18-202$ & 897 & 14.44 & 5.82 & $<0.001$ \\
\hline
\end{tabular}

All reported effects are tested at $\alpha=0.05$; FWE-corrected for the search volume; $\mathrm{k}>10$.

Table 2. EEG statistics; main effects

\begin{tabular}{lllr}
\hline ERP & $t$ & df & \multicolumn{1}{c}{$p$} \\
\hline CNV1 & 4.08 & 13 & 0.001 \\
CNV2 & 6.18 & 13 & $<0.001$ \\
\hline
\end{tabular}

The condition-dependent CNV effects remain significant after selecting RT-matched trials only (CNV1: $t_{(13)}=3.13$;

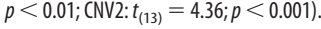

network including VS, THAL, and SMA was clearly detectable (Table 1 shows fMRI statistics).

\section{EEG main effects}

Figure $1 B, C$ shows the grand-average waveforms at the $\mathrm{Cz}$ electrode site of the CNV for monetary reward anticipation and control conditions along with the EEG channel scheme and scalp topography of the CNV. Highly significant condition effects (monetary reward anticipation $>$ control) were found for both CNV phases (Table 2 shows EEG statistics).

\section{Joint EEG-fMRI analysis}

Analyzing the correlation of the CNV measures with the BOLD response amplitudes across subjects revealed a network comprising the cerebellum, THAL, mid-brain structures, insula, SMA, sensorimotor areas, and parietal cortices. Hypothesis-driven analyses of the correlation between the CNV and BOLD responses in the predefined ROIs revealed significant correlations in VS, THAL, and SMA (Fig. $2 A-C$ ).

Trial-to-trial analyses (see Materials and Methods) revealed a similar correlation network including the identical structures as listed above. However, the effects were relatively small compared with the second-level correlations and did not survive correction for multiple testing.

Intermodal correlation effects were consistently stronger for CNV1 compared with CNV2. Therefore, further analyses focused on CNV1.

Mediation analyses showed that the relationship between both ROIs (VS and SMA) and the CNV1 measure was fully mediated by thalamic activation (Fig. 3; Table 3). Importantly, the converse was not true, i.e., the relation between thalamic activation and CNV1 did not significantly change after the inclusion of VS or SMA as mediator variables.

\section{DCM analyses}

RFX BMS revealed one clear winner model describing the underlying neuronal activity best: the fully connected model had a model exceedance probability of 0.71 in a model space of 32 models where all probabilities sum up to 1 (Fig. $4 A$ ). This supports the hypothesis that all three nodes in the network are reciprocally connected and are influencing each other.

Extracting the parameters of the winning model revealed a strong intrinsic excitatory influence of the THAL on both the VS and SMA. In addition, VS showed an inhibitory influence on the
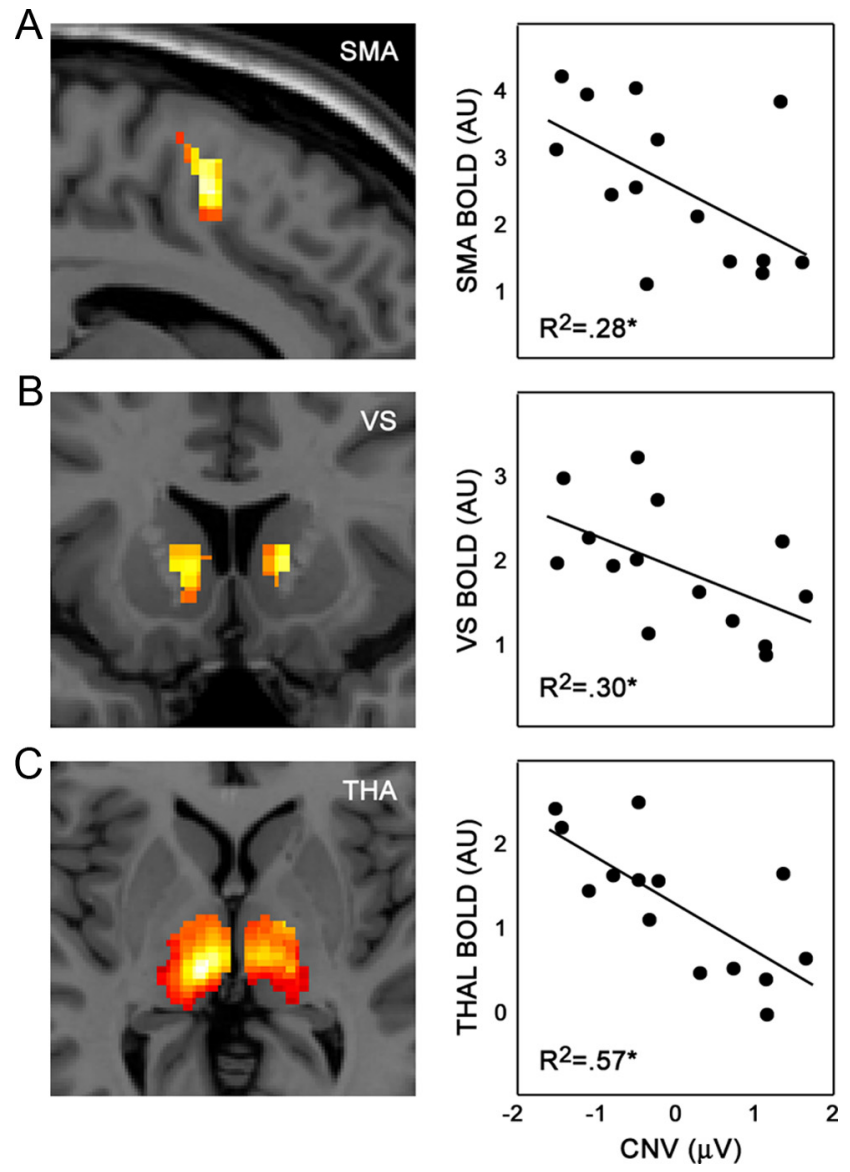

Figure 2. Significant correlation of the CNV amplitude (difference score: monetary reward anticipation $>$ control) and BOLD FMRI signal (monetary reward anticipation $>$ control) within the predefined ROIs ( $\boldsymbol{A}, \mathrm{SMA} ; \boldsymbol{B}, \mathrm{VS} ; \boldsymbol{C}$, THAL). The scatterplots show ROI average BOLD signal of all voxels within VS, SMA, and THA ROI. Note that results for CNV1 are shown and that the effects for CNV2 are consistently weaker (data not shown).

SMA (Fig. 4B). To further elucidate whether a physiologically plausible surrogate of the revealed full mediation by THAL exists, the modulation of the network by the monetary reward anticipation condition was analyzed. The monetary reward anticipation condition led to a decrease in the drive from THAL to SMA and to an increase in its drive to the VS, i.e., the influence of the VS on the SMA became excitatory during the monetary reward anticipation condition (Fig. 4C).

\section{DCM-CNV relationship}

To explore whether DCM parameters explain additional variance of the CNV, stepwise multiple regression (inclusion criterion $p<$ 0.10 ) was applied with the BOLD contrast estimates of THAL, VS, and SMA together with the six DCM parameters for the modulated network as predictors for the CNV. This procedure identified a model consisting of THAL activation and two DCM parameters: SMA $\rightarrow$ VS and SMA $\rightarrow$ THAL connectivity modulation (model statistics: $F_{(3,10)}=11.6 ; p<0.001$; adjusted $R^{2}=.71$ ). This model which combines BOLD activation and DCM connectivity parameters explained significantly more variance than THAL BOLD effects alone. These results suggest that beyond a strong thalamic activation impact, the scalp-recorded CNV signal contains a significant amount of SMA-mediated top-down regulatory processes (Fig. 5). 


\section{Discussion}

In the present simultaneous EEG-fMRI study on reward anticipation, we investigated intermodal correlations between two widely known reward anticipation signals, namely the $\mathrm{AMRI}$ BOLD response in the VS, and the CNV observed in EEG. Using a modified version of a highly reliable fMRI reward task (Kirsch et al., 2003; Plichta et al., 2012) we showed that (1) the simultaneously recorded CNV component is detectable and sensitive to the experimental conditions, (2) THAL fMRI BOLD activity is mediating intermodal correlations between the CNV1 signal and the FMRI BOLD response in SMA and VS, (3) the underlying causal connectivity network consists of top-down regulation from SMA to VS and SMA to THAL along with an excitatory information flow through a $\mathrm{THAL} \rightarrow \mathrm{VS} \rightarrow \mathrm{SMA}$ route during reward anticipation, and (4) the EEG CNV1 signal is best predicted by a combination of THAL $\mathrm{MMRI}$ BOLD response and strength of top-down regulation from SMA to VS and SMA to THAL.

The correlation of anticipatory BOLD signals and connectivity parameters with the scalp-recorded CNV1 component suggests that these two signals share similar neural mechanisms. This finding adds to the weight of evidence implied by many previous EEG studies (for review, see Broyd et al., 2012a) but direct empirical evidence has so far been lacking. However, it must be noted that such correlations do not imply that the measured EEG signals stem directly or exclusively from these subcortical regions (Cohen et al., 2009, 2011). Alternatively, top-down regulatory processes from the frontal cortex to the striatum (Cohen et al., 2012) as captured by the scalp-recorded CNV1 might include information about VS BOLD activity.

The revealed network presented in Figure 4 is in line with the understanding that thalamic nuclei supply striatal neurons with information of behaviorally significant events (Matsumoto et al., 2001). Behaviorally significant events transmitted along the thalamostriatal projections, in coordination with the motivational value of the dopamine inputs, are therefore a precursor for proper action selection through the basal ganglia-thalamocorticalstriatal circuitry (Smith et al., 2004). Interestingly, direct THAL connectivity to motor areas including the SMA has been shown in the primate brain (Fang et al., 2006) and in the present study were found to be the most dominant excitatory link in the intrinsic connectivity model (Fig. 4B). An integrative view for the modulated network pattern would be that THAL is acting on VS via thalamostriatal connections (Groenewegen and Berendse, 1994; Kimura et al., 2004; activation effects.
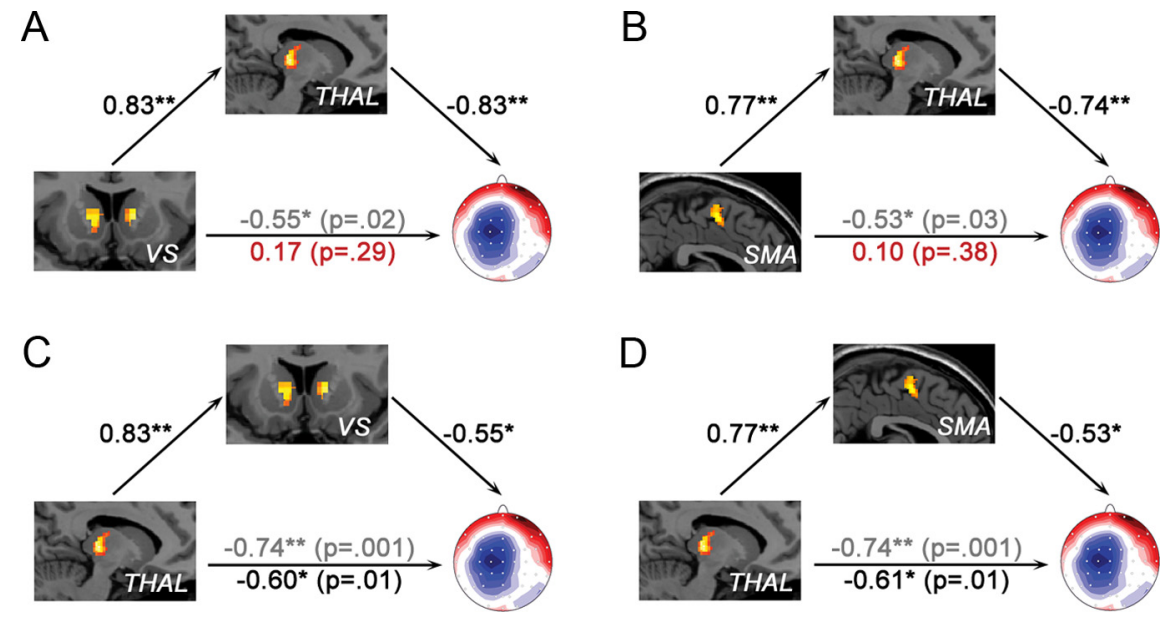

Figure 3. Mediation analyses. Relation between the EEG CNV and the fMRI response $(\boldsymbol{A})$ in the VS and (B) in the SMA is fully mediated by the THAL, i.e., the significance of bivariate relations (gray numbers) fully vanishes (red numbers) when THAL thalamus is considered as a mediator. Note that the converse is not true, i.e., the relation between the thalamic fMRI response and the EEG CNV is not significantly reduced when either the VS $(\boldsymbol{C})$ or the SMA $(\boldsymbol{D})$ is included as a mediator. Numbers are correlation coefficients; ${ }^{*} p<0.05 ;{ }^{* *} p<0.01$.

Table 3. Mediation analysis

\begin{tabular}{llcl}
\hline Indirect effect & Mediator & Effect size with 95\% Cl & Sobel test, Z $(p)$ \\
\hline VS $\rightarrow$ CNV & THAL & $-1.08(-1.94-0.29)^{\mathrm{a}}$ & $2.23(0.03)^{\mathrm{b}}$ \\
SMA $\rightarrow$ CNV & THAL & $-0.61(-1.23-0.20)^{\mathrm{a}}$ & $2.13(0.03)^{\mathrm{b}}$ \\
THAL $\rightarrow$ CNV & VS & $0.23(-0.45-1.00)$ & $0.57(0.57)$ \\
THAL $\rightarrow$ CNV & SMA & $0.09(-0.60-1.05)$ & $0.29(0.77)$ \\
\hline
\end{tabular}

aSignificantly different from zero at $p<0.05$ (two-tailed).

$\mathrm{b}_{p}<0.05$ (two-tailed).
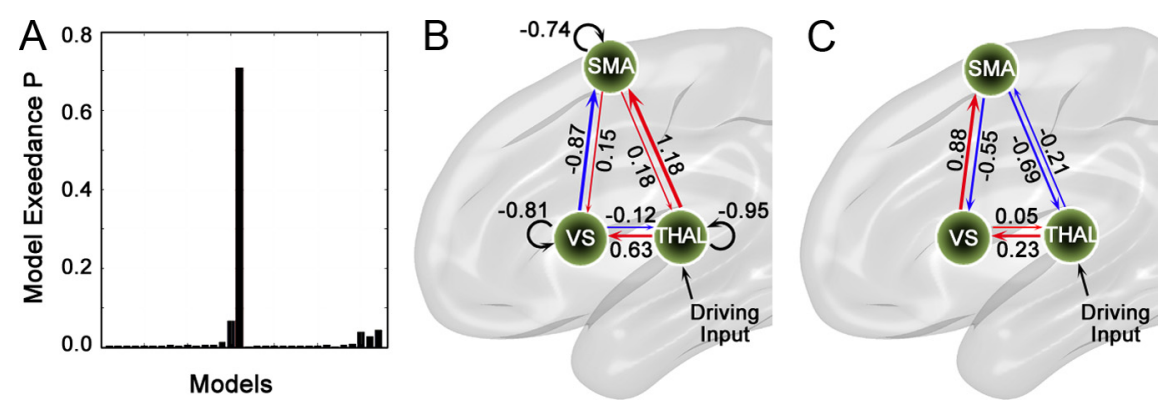

Figure 4. Results of the DCM analyses. The exceedance probabilities resulting from the BMS for the 32 models are shown in $\boldsymbol{A}$. The fully connected model is the clear winner $(p=0.71)$. $\boldsymbol{B}$, The endogenous connectivity, i.e., connectivity regardless of task demands. $C$, Modulation of connectivity due to monetary reward anticipation.

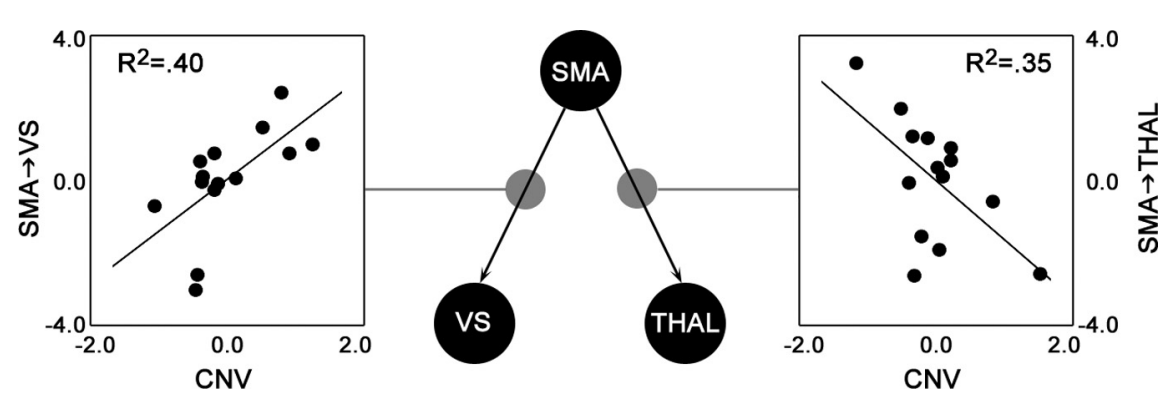

Figure 5. Partial regression plots showing the relationship of the modulated DCM parameters from SMA $\rightarrow$ VS (left) and $\mathrm{SMA} \rightarrow$ THAL (right) with the CNV amplitude (difference score: monetary reward anticipation $>$ control) beyond pure THAL BOLD 
Smith et al., 2004, 2009) signaling increased arousal and vigilance (Kinomura et al., 1996) associated with the anticipated monetary reward versus the control condition. The VS influence on the SMA, e.g., to enhance and/or suppress action related signals, does not necessarily imply a monosynaptic connection. Alternatively, the VS can act on frontal cortex via direct projections to the nucleus basalis in the basal forebrain which is the main source of cholinergic fibers (Haber, 2011). VS, in turn, is influenced by top-down-directed modulation from the medial prefrontal cortex as shown by Cohen et al. (2012). Termination of this signal flow in the SMA finally reactivates the thalamus via reciprocal corticothalamic projections (Haber and Calzavara, 2009).

From a practical perspective, the intermodal correlation we report here potentially provides a surface EEG, and therefore likely cortical, surrogate for neural processes during reward anticipation including modulation of VS activity. The human dopaminergic reward system can be directly stimulated by drugs of abuse such as cocaine (Breiter et al., 1997) and modulated by dopamine releasers like amphetamine (Knutson et al., 2004) or neuroleptic drugs (Abler et al., 2007). Therefore, anticipatory VS responsivity has become an attractive target for pharmaco-fMRI studies, i.e., studies wherein pharmacological compounds are administered to modulate the brain's response to task-based fMRI paradigms (Kassubek et al., 2011; Gilman et al., 2012; van Hell et al., 2012; van Wouwe et al., 2012). Given that EEG recordings are less demanding than fMRI, both technically and financially, identification of an EEG surrogate for reward anticipation would provide a useful alternative methodology to probe this brain system. To date, pharmaco-EEG studies have focused on feedbackrelated brain activity (Santesso et al., 2009) or CNV without reward-modulation (Kratz et al., 2012). Our results supply future pharmaco-EEG studies with an EEG surrogate more specific to reward anticipatory effects including modulation of VS activity. Again, the thalamic transmission in combination with top-down regulation from SMA to VS and THAL identified in our pathway analysis would be a likely neurobiological mechanism mapping a primarily subcortical process onto a cortical signature.

Although the CNV amplitude was significantly correlated with the fMRI signals measured in the VS and the THAL, it is highly unlikely that the measured EEG signal is generated in these subcortical regions. For example, neurons within the VS do not have a geometrically parallel organization like cortical pyramidal cells. Therefore, it is implausible that potentials from the striatum propagate to the scalp (Cohen et al., 2011). On the other hand, even brainstem structures generate EEG signals detectable through averaging (Jewett et al., 1970) and at least one recent positive report about scalp-measured subcortical EEG exists that needs further replication (Foti et al., 2011). However, even when the CNV signal, significantly correlated with fMRI VS signal, has a different origin the correlation itself is a predictor of VS activity and our DCM analysis support the assumption that the thalamic and VS signal modulate at least one important generator of the cortical CNV in the SMA. Correlation of CNV amplitudes with experimentally induced VS changes would be a critical prerequisite that could be tested by future studies.

\section{Limitations}

Using only two anticipation conditions and immediate feedback to ensure enough trials for EEG averaging in the applied paradigm still yielded typical reward anticipation effects unlike plain attentional or motor activation patterns. Studies with additional control conditions have identified contributions of valence and salience (Diekhof et al., 2012), and excluded confounds from unspecific activation (Kirsch et al., 2003), or arousal and motor preparation (Damen and Brunia, 1987; Kotani et al., 2001; Dillon et al., 2009). Specificity of our results by means of potential differences in monetary win versus loss anticipation cannot be tested. However, RT matched CNV data (Table 2) showed that pure motor preparation effects cannot explain the revealed differences between the experimental conditions (Sobotka et al., 1992).

Because of the subjects' motor responses and related artifacts we could not analyze target- or feedback-related EEG components (Broyd et al., 2012a). To achieve this, further modification of the reward paradigm would be necessary, i.e., the introduction of a larger delay period between response and feedback.

Joint EEG-fMRI trial-to-trial analysis might offer an interesting possibility of additional analysis (Bland et al., 2011) because of its' sensitivity for dynamic effects potentially revealing the involvement of additional brain regions (Scheibe et al., 2010). Recent studies have begun to focus on correlations of momentto-moment fluctuations and behavior (Fox et al., 2007; Mars et al., 2008). However, because the trial-to-trial fluctuation effects in our study were rather small in size, further modifications of the applied reward paradigm would again seem to be necessary to make it more suitable for EEG recordings and this type of analysis. For example, single-trial analysis suffers from the superposition of task-relevant signals by task-unrelated "background" brain activity. Therefore, the resulting signal-to-noise ratio (SNR) of the observed single trial is expected to be rather low. Methodological studies should investigate the suitability of the reward task for single-trial analysis in combination using sophisticated statistical approaches (Debener et al., 2006). For the present study, our primary aim was to increase the trial number from 10 (Plichta et al., 2012) to 50 to improve the SNR in the EEG responses but other characteristics, such as the time interval between S1 and S2, could be reconsidered as well (Birbaumer et al., 1990).

Finally, the impact of different fMRI preprocessing strategies (e.g., smoothing kernel) on localization of reward-related brain activity (Sacchet and Knutson, 2012) was not tested here but should be considered in future studies.

\section{Conclusions}

In a simultaneous EEG-fMRI study on reward anticipation, we have demonstrated intermodal correlations between two widely known fMRI and EEG signals sensitive to reward anticipation, namely BOLD response within core structures of a reward anticipation network and the EEG CNV signal. We showed that (1) THAL fMRI BOLD activity is mediating intermodal correlations between the EEG CNV1 signal and the fMRI BOLD response in SMA and VS, (2) the underlying causal connectivity network consists of top-down regulation from SMA to VS and SMA to THAL along with an excitatory information flow through a $\mathrm{THAL} \rightarrow \mathrm{VS} \rightarrow \mathrm{SMA}$ route during reward anticipation, and (3) the EEG CNV signal is best predicted by a combination of THAL fMRI BOLD response and strength of top-down regulation from SMA to VS and SMA to THAL. The intermodal correlations enable predictions of the responsiveness of the reward anticipation network based on a scalp surface recorded EEG signal.

\section{References}

Abler B, Erk S, Walter H (2007) Human reward system activation is modulated by a single dose of olanzapine in healthy subjects in an event-related, double-blind, placebo-controlled fMRI study. Psychopharmacology 191: 823-833. CrossRef Medline 
Allen PJ, Polizzi G, Krakow K, Fish DR, Lemieux L (1998) Identification of EEG events in the MR scanner: the problem of pulse artifact and a method for its subtraction. Neuroimage 8:229-239. CrossRef Medline

Allen PJ, Josephs O, Turner R (2000) A method for removing imaging artifact from continuous EEG recorded during functional MRI. Neuroimage 12:230-239. CrossRef Medline

Baron RM, Kenny DA (1986) The moderator-mediator variable distinction in social psychological research: conceptual, strategic, and statistical considerations. J Pers Soc Psychol 51:1173-1182. CrossRef Medline

Birbaumer N, Elbert T, Canavan AG, Rockstroh B (1990) Slow potentials of the cerebral cortex and behavior. Physiol Rev 70:1-41. Medline

Bland AR, Mushtaq F, Smith DV (2011) Exploiting trial-to-trial variability in multimodal experiments. Front Hum Neurosci 5:80. CrossRef Medline

Boyd ES, Boyd EH, Brown LE (1979) Observations on the M-wave and the CNV in the squirrel monkey. Electroencephalogr Clin Neurophysiol 46: 320-336. CrossRef Medline

Breiter HC, Gollub RL, Weisskoff RM, Kennedy DN, Makris N, Berke JD, Goodman JM, Kantor HL, Gastfriend DR, Riorden JP, Mathew RT, Rosen BR, Hyman SE (1997) Acute effects of cocaine on human brain activity and emotion. Neuron 19:591-611. CrossRef Medline

Broyd SJ, Richards HJ, Helps SK, Chronaki G, Bamford S, Sonuga-Barke EJ (2012a) An electrophysiological monetary incentive delay (e-MID) task: a way to decompose the different components of neural response to positive and negative monetary reinforcement. J Neurosci Methods 209:40 - 49. CrossRef Medline

Broyd SJ, Richards HJ, Helps SK, Chronaki G, Bamford S, Sonuga-Barke EJ (2012b) Electrophysiological markers of the motivational salience of delay imposition and escape. Neuropsychologia 50:965-972. CrossRef Medline

Capa RL, Bouquet CA, Dreher JC, Dufour A (2013) Long-lasting effects of performance-contingent unconscious and conscious reward incentives during cued task-switching. Cortex 49:1943-1954. CrossRef Medline

Cohen MX, Axmacher N, Lenartz D, Elger CE, Sturm V, Schlaepfer TE (2009) Neuroelectric signatures of reward learning and decision-making in the human nucleus accumbens. Neuropsychopharmacology 34:16491658. CrossRef Medline

Cohen MX, Cavanagh JF, Slagter HA (2011) Event-related potential activity in the basal ganglia differentiates rewards from nonrewards: temporospatial principal components analysis and source localization of the feedback negativity: commentary. Hum Brain Mapp 32:2270-2271. CrossRef Medline

Cohen MX, Bour L, Mantione M, Figee M, Vink M, Tijssen MA, van Rootselaar AF, van den Munckhof P, Schuurman PR, Denys D (2012) Topdown-directed synchrony from medial frontal cortex to nucleus accumbens during reward anticipation. Hum Brain Mapp 33:246-252. CrossRef Medline

Damen EJ, Brunia CH (1987) Changes in heart rate and slow brain potentials related to motor preparation and stimulus anticipation in a time estimation task. Psychophysiology 24:700-713. CrossRef Medline

Debener S, Ullsperger M, Siegel M, Engel AK (2006) Single-trial EEG-fMRI reveals the dynamics of cognitive function. Trends Cogn Sci 10:558-563. CrossRef Medline

Debener S, Mullinger KJ, Niazy RK, Bowtell RW (2008) Properties of the ballistocardiogram artefact as revealed by EEG recordings at $1.5,3$ and $7 \mathrm{~T}$ static magnetic field strength. Int J Psychophysiol 67:189-199. CrossRef Medline

Diekhof EK, Kaps L, Falkai P, Gruber O (2012) The role of the human ventral striatum and the medial orbitofrontal cortex in the representation of reward magnitude- an activation likelihood estimation meta-analysis of neuroimaging studies of passive reward expectancy and outcome processing. Neuropsychologia 50:1252-1266. CrossRef Medline

Dillon DG, Holmes AJ, Birk JL, Brooks N, Lyons-Ruth K, Pizzagalli DA (2009) Childhood adversity is associated with left basal ganglia dysfunction during reward anticipation in adulthood. Biol Psychiatry 66:206213. CrossRef Medline

Fang PC, Stepniewska I, Kaas JH (2006) The thalamic connections of motor, premotor, and prefrontal areas of cortex in a prosimian primate (Otolemur garnetti). Neuroscience 143:987-1020. CrossRef Medline

Forbes EE, Brown SM, Kimak M, Ferrell RE, Manuck SB, Hariri AR (2009) Genetic variation in components of dopamine neurotransmission impacts ventral striatal reactivity associated with impulsivity. Mol Psychiatry 14:60-70. CrossRef Medline
Forbes EE, Olino TM, Ryan ND, Birmaher B, Axelson D, Moyles DL, Dahl RE (2010) Reward-related brain function as a predictor of treatment response in adolescents with major depressive disorder. Cogn Affect Behav Neurosci 10:107-118. CrossRef Medline

Foti D, Weinberg A, Dien J, Hajcak G (2011) Event-related potential activity in the basal ganglia differentiates rewards from nonrewards: temporospatial principal components analysis and source localization of the feedback negativity. Hum Brain Mapp 32:2207-2216. CrossRef Medline

Fox MD, Snyder AZ, Vincent JL, Raichle ME (2007) Intrinsic fluctuations within cortical systems account for intertrial variability in human behavior. Neuron 56:171-184. CrossRef Medline

Friston KJ, Harrison L, Penny W (2003) Dynamic causal modelling. Neuroimage 19:1273-1302. CrossRef Medline

Gilman JM, Smith AR, Ramchandani VA, Momenan R, Hommer DW (2012) The effect of intravenous alcohol on the neural correlates of risky decision making in healthy social drinkers. Addict Biol 17:465-478. CrossRef Medline

Gómez CM, Marco J, Grau C (2003) Preparatory visuo-motor cortical network of the contingent negative variation estimated by current density. Neuroimage 20:216-224. CrossRef Medline

Groenewegen HJ, Berendse HW (1994) The specificity of the "nonspecific" midline and intralaminar thalamic nuclei. Trends Neurosci 17:52-57. CrossRef Medline

Haber SN (2011) Neuroanatomy of reward: a view from the ventral striatum. In: Source Neurobiology of Sensation and Reward (Gottfried JA, ed). Boca Raton, FL: CRC.

Haber SN, Calzavara R (2009) The cortico-basal ganglia integrative network: the role of the thalamus. Brain Res Bull 78:69-74. CrossRef Medline

Hahn T, Dresler T, Ehlis AC, Plichta MM, Heinzel S, Polak T, Lesch KP, Breuer F, Jakob PM, Fallgatter AJ (2009) Neural response to reward anticipation is modulated by Gray's impulsivity. Neuroimage 46: 1148-1153. CrossRef Medline

Hahn T, Heinzel S, Dresler T, Plichta MM, Renner TJ, Markulin F, Jakob PM, Lesch KP, Fallgatter AJ (2011) Association between reward-related activation in the ventral striatum and trait reward sensitivity is moderated by dopamine transporter genotype. Hum Brain Mapp 32:1557-1565. CrossRef Medline

Hayes AF (2012) PROCESS: a versatile computational tool for observed variable mediation, moderation, and conditional process modeling [white paper]. Retrieved from: http://www.afhayes.com/public/process2012.pdf.

Jewett DL, Romano MN, Williston JS (1970) Human auditory evoked potentials: possible brain stem components detected on the scalp. Science 167:1517-1518. CrossRef Medline

Juckel G, Friedel E, Koslowski M, Witthaus H, Ozgürdal S, Gudlowski Y, Knutson B, Wrase J, Brüne M, Heinz A, Schlagenhauf F (2012) Ventral striatal activation during reward processing in subjects with ultra-high risk for schizophrenia. Neuropsychobiology 66:50-56. CrossRef Medline

Kassubek J, Abler B, Pinkhardt EH (2011) Neural reward processing under dopamine agonists: imaging. J Neurol Sci 310:36-39. CrossRef Medline

Kimura M, Minamimoto T, Matsumoto N, Hori Y (2004) Monitoring and switching of cortico-basal ganglia loop functions by the thalamo-striatal system. Neurosci Res 48:355-360. CrossRef Medline

Kinomura S, Larsson J, Gulyás B, Roland PE (1996) Activation by attention of the human reticular formation and thalamic intralaminar nuclei. Science 271:512-515. CrossRef Medline

Kirsch P, Schienle A, Stark R, Sammer G, Blecker C, Walter B, Ott U, Burkart J, Vaitl D (2003) Anticipation of reward in a nonaversive differential conditioning paradigm and the brain reward system: an event-related fMRI study. Neuroimage 20:1086-1095. CrossRef Medline

Kirsch P, Reuter M, Mier D, Lonsdorf T, Stark R, Gallhofer B, Vaitl D, Hennig $J$ (2006) Imaging gene-substance interactions: the effect of the DRD2 TaqIA polymorphism and the dopamine agonist bromocriptine on the brain activation during the anticipation of reward. Neurosci Lett 405: 196-201. CrossRef Medline

Knutson B, Cooper JC (2005) Functional magnetic resonance imaging of reward prediction. Curr Opin Neurol 18:411-417. CrossRef Medline

Knutson B, Bjork JM, Fong GW, Hommer D, Mattay VS, Weinberger DR (2004) Amphetamine modulates human incentive processing. Neuron 43:261-269. CrossRef Medline

Knutson B, Adams CM, Fong GW, Hommer D (2001a) Anticipation of 
increasing monetary reward selectively recruits nucleus accumbens. J Neurosci 21:RC159. Medline

Knutson B, Fong GW, Adams CM, Varner JL, Hommer D (2001b) Dissociation of reward anticipation and outcome with event-related fMRI. Neuroreport 12:3683-3687. CrossRef Medline

Kotani Y, Hiraku S, Suda K, Aihara Y (2001) Effect of positive and negative emotion on stimulus-preceding negativity prior to feedback stimuli. Psychophysiology 38:873-878. CrossRef Medline

Kratz O, Studer P, Baack J, Malcherek S, Erbe K, Moll GH, Heinrich H (2012) Differential effects of methylphenidate and atomoxetine on attentional processes in children with ADHD: an event-related potential study using the attention network test. Prog Neuropsychopharmacol Biol Psychiatry 37:81-89. CrossRef Medline

Liu X, Hairston J, Schrier M, Fan J (2011) Common and distinct networks underlying reward valence and processing stages: a meta-analysis of functional neuroimaging studies. Neurosci Biobehav Rev 35:1219-1236. CrossRef Medline

Mars RB, Debener S, Gladwin TE, Harrison LM, Haggard P, Rothwell JC, Bestmann S (2008) Trial-by-trial fluctuations in the event-related electroencephalogram reflect dynamic changes in the degree of surprise. J Neurosci 28:12539-12545. CrossRef Medline

Matsumoto N, Minamimoto T, Graybiel AM, Kimura M (2001) Neurons in the thalamic CM-Pf complex supply striatal neurons with information about behaviorally significant sensory events. J Neurophysiol 85:960976. Medline

Nagai Y, Critchley HD, Featherstone E, Fenwick PB, Trimble MR, Dolan RJ (2004) Brain activity relating to the contingent negative variation: an fMRI investigation. Neuroimage 21:1232-1241. CrossRef Medline

Pierson A, Ragot R, Ripoche A, Lesevre N (1987) Electrophysiological changes elicited by auditory stimuli given a positive or negative value: a study comparing anhedonic with hedonic subjects. Int J Psychophysiol 5:107-123. CrossRef Medline

Plichta MM, Vasic N, Wolf RC, Lesch KP, Brummer D, Jacob C, Fallgatter AJ, Grön G (2009) Neural hyporesponsiveness and hyperresponsiveness during immediate and delayed reward processing in adult attention-deficit/hyperactivity disorder. Biol Psychiatry 65:7-14. CrossRef Medline

Plichta MM, Schwarz AJ, Grimm O, Morgen K, Mier D, Haddad L, Gerdes AB, Sauer C, Tost H, Esslinger C, Colman P, Wilson F, Kirsch P, MeyerLindenberg A (2012) Test-retest reliability of evoked BOLD signals from a cognitive-emotive fMRI test battery. Neuroimage 60:1746-1758. CrossRef Medline

Preacher KJ, Hayes AF (2004) SPSS and SAS procedures for estimating indirect effects in simple mediation models. Behav Res Methods Instrum Comput 36:717-731. CrossRef Medline

Riba J, Krämer UM, Heldmann M, Richter S, Münte TF (2008) Dopamine agonist increases risk taking but blunts reward-related brain activity. PLoS One 3:e2479. CrossRef Medline

Rohrbaugh JW, Syndulko K, Lindsley DB (1976) Brain wave components of the contingent negative variation in humans. Science 191:1055-1057. CrossRef Medline
Sacchet MD, Knutson B (2012) Spatial smoothing systematically biases the localization of reward-related brain activity. Neuroimage 66C:270-277. Medline

Santesso DL, Evins AE, Frank MJ, Schetter EC, Bogdan R, Pizzagalli DA (2009) Single dose of a dopamine agonist impairs reinforcement learning in humans: evidence from event-related potentials and computational modeling of striatal-cortical function. Hum Brain Mapp 30:1963-1976. CrossRef Medline

Scheibe C, Ullsperger M, Sommer W, Heekeren HR (2010) Effects of parametrical and trial-to-trial variation in prior probability processing revealed by simultaneous electroencephalogram/functional magnetic resonance imaging. J Neurosci 30:16709-16717. CrossRef Medline

Scheres A, Milham MP, Knutson B, Castellanos FX (2007) Ventral striatal hyporesponsiveness during reward anticipation in attention-deficit/hyperactivity disorder. Biol Psychiatry 61:720-724. CrossRef Medline

Smith Y, Raju DV, Pare JF, Sidibe M (2004) The thalamostriatal system: a highly specific network of the basal ganglia circuitry. Trends Neurosci 27:520-527. CrossRef Medline

Smith Y, Raju D, Nanda B, Pare JF, Galvan A, Wichmann T (2009) The thalamostriatal systems: anatomical and functional organization in normal and parkinsonian states. Brain Res Bull 78:60-68. CrossRef Medline

Sobotka SS, Davidson RJ, Senulis JA (1992) Anterior brain electrical asymmetries in response to reward and punishment. Electroencephalogr Clin Neurophysiol 83:236-247. CrossRef Medline

Stephan KE, Harrison LM, Kiebel SJ, David O, Penny WD, Friston KJ (2007) Dynamic causal models of neural system dynamics: current state and future extensions. J Biosci 32:129-144. CrossRef Medline

Stephan KE, Penny WD, Daunizeau J, Moran RJ, Friston KJ (2009) Bayesian model selection for group studies. Neuroimage 46:1004-1017. CrossRef Medline

Stephan KE, Penny WD, Moran RJ, den Ouden HE, Daunizeau J, Friston KJ (2010) Ten simple rules for dynamic causal modeling. Neuroimage 49: 3099-3109. CrossRef Medline

van Hell HH, Jager G, Bossong MG, Brouwer A, Jansma JM, Zuurman L, van Gerven J, Kahn RS, Ramsey NF (2012) Involvement of the endocannabinoid system in reward processing in the human brain. Psychopharmacology 219:981-990. CrossRef Medline

van Leeuwen TH, Steinhausen HC, Overtoom CC, Pascual-Marqui RD, van't Klooster B, Rothenberger A, Sergeant JA, Brandeis D (1998) The continuous performance test revisited with neuroelectric mapping: impaired orienting in children with attention deficits. Behav Brain Res 94:97-110. CrossRef Medline

van Wouwe NC, Ridderinkhof KR, Band GP, van den Wildenberg WP, Wylie SA (2012) Dose-dependent dopaminergic modulation of reward-based learning in Parkinson's disease. Neuropsychologia 50:583-591. CrossRef Medline

Walter WG, Cooper R, Aldridge VJ, McCallum WC, Winter AL (1964) Contingent negative variation: an electric sign of sensorimotor association and expectancy in the human brain. Nature 203:380-384. CrossRef Medline 